\title{
Crossed Cerebellar Diaschisis: Risk Factors and Correlation to Functional Recovery in Intracerebral Hemorrhage
}

\author{
Deok Su Sin, MD' ${ }^{1}$, Myoung Hyoun Kim, MD², Soon-Ah Park, MD², \\ Min Cheol Joo, $\mathrm{MD}^{1}$, Min Su Kim, MD \\ Departments of ${ }^{1}$ Rehabilitation Medicine and ${ }^{2}$ Nuclear Medicine, \\ Wonkwang University School of Medicine \& Hospital, Iksan, Korea
}

Objective The purpose of this study is to investigate predictors of crossed cerebellar diaschisis (CCD), and the effects of CCD on functional outcomes including motor function, activities of daily living, cognitive function, and ambulation 6 months after onset in patients with intracerebral hemorrhage (ICH).

Methods A total of 74 patients experiencing their first ICH were recruited. If the asymmetric index was more than $10 \%$ using single photon emission computed tomography (SPECT), a diagnosis of CCD was confirmed. Clinical factors were retrospectively assessed by reviewing medical records. Radiologic factors encompassed the concomitance of intraventricular hemorrhage, side and location of the lesion, and hemorrhage volume. Functional outcomes were evaluated using the Fugl-Meyer Assessment, the Korean version of the Mini-Mental State Examination, the Korean version of the Modified Barthel Index, and measurement of the Functional Ambulatory Category at the time of SPECT measurement and 6 months post-ICH.

Results Lesion location, especially in the basal ganglia (odds ratio $[\mathrm{OR}]=6.138, \mathrm{p}=0.011$ ), and hemorrhagic volume $(\mathrm{OR}=1.055, \mathrm{p}=0.046)$ were independent predictors for CCD according to multivariate logistic regression analysis. In addition, the presence of CCD was significantly related to the improvement in Fugl-Meyer Assessment score after 6 months (adjusted $\mathrm{R}^{2}=0.152, \mathrm{p}=0.036$ ).

Conclusion Lesion location and hemorrhagic volume were the predisposing factors for CCD, and the CCD was associated with poor motor recovery over 6 months in patients with hemorrhagic stroke.

Keywords Cerebellum, Cerebral hemorrhage, Recovery of function, Risk factors, Single-photon emissioncomputed tomography

Department of Rehabilitation Medicine, Wonkwang University School of Medicine \& Hospital, 895 Muwang-ro, Iksan 54538, Korea. Tel: +82-63-8591610, Fax: +82-63-843-1385, E-mail: helmaine@naver.com

ORCID: Deok Su Sin (http://orcid.org/0000-0001-5920-6925); Myoung Hyoun Kim (http://orcid.org/0000-0002-4541-8019); Soon-Ah Park (http:// orcid.org/0000-0002-8269-8865); Min Cheol Joo (http://orcid.org/0000-0003-2778-4194); Min Su Kim (http://orcid.org/0000-0001-9954-1445).

() This is an open-access article distributed under the terms of the Creative Commons Attribution Non-Commercial License (http://creativecommons.org/ licenses/by-nc/4.0) which permits unrestricted noncommercial use, distribution, and reproduction in any medium, provided the original work is properly cited. Copyright $\odot 2018$ by Korean Academy of Rehabilitation Medicine 


\section{INTRODUCTION}

Crossed cerebellar diaschisis (CCD) is a phenomenon involving a decrease in metabolic activity and cerebellar blood flow contralateral to the supratentorial brain lesion [1]. The incidence of CCD after supratentorial stroke ranges from $15.6 \%$ to $46.2 \%$ [2]. The mechanism of CCD was proposed to be related to the interruption of the corticopontocerebellar tract [3-5], which may be caused by stroke, tumor, arteriovenous malformations, epilepsy, or encephalitis. Additionally, other tracts including the spinocerebellar [6] and dentatorubrothalamic tracts [7] were proposed to be involved in CCD pathogenesis.

There were several assumptions regarding the factors associated with CCD. Many researchers argued that a huge infarction volume $[8,9]$, and the severity of impaired perfusion [10] are related CCD. Other studies indicated that the location of stroke [11] or side of the lesion [2] is associated with CCD. Additionally, the association between CCD and functional outcome is still under debate. It is unclear whether CCD is correlated to outcomes $[10,12,13]$ or not related $[14,15]$. Even authors who agree that there is an association between CCD and issues, have yet to clarify if motor function $[12,16,17]$, activities of daily living (ADL) [13], or global function [10] are associated with CCD.

Although many previous studies have attempted to explain the predisposing factors of CCD or the relationship between outcomes and CCD, most were concerned with ischemic stroke. Even researchers who investigated patients with hemorrhage also involved patients with isch- emic stroke, which made participants heterogeneous. A few reports were aimed at hemorrhagic stroke patients solely. This study was therefore designed to clarify the risk factors for CCD and investigate the relationship of CCD with outcomes including motor function, cognitive function, ADLs, and mobility in patients experiencing their first supratentorial hemorrhage.

\section{MATERIALS AND METHODS}

\section{Participants}

We reviewed the medical records of patients who visited our hospital from January 2011 to December 2015 diagnosed with their first supratentorial intracerebral hemorrhage (ICH) (Fig. 1). Computed tomography (CT) (SOMATOM Definition Flash; Siemens, Munich, Germany) was performed in every patient upon arrival at the emergency room (ER). All patients were diagnosed with ICH by a neurosurgeon or neuroradiologist based on the CT results. Among these patients, we selected those who were referred to a rehabilitation department and underwent single photon emission computed tomography (SPECT) during admission (Fig. 2). Patients were excluded when they met the following criteria: (1) past medical history of diseases affecting motor function, ADL, and mobility outcomes; (2) past medical history of conditions affecting cognitive function; and (3) inability to ambulate independently before the onset of ICH. This study was approved by the Institutional Review Board of Wonkwang University Hospital (IRB No. WKUH 201601-HRE-006).

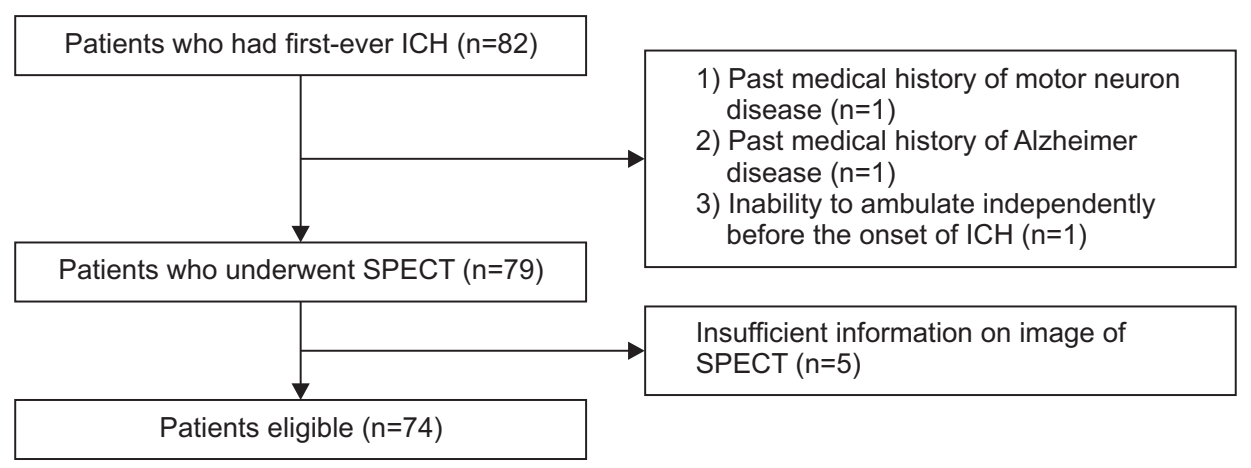

Fig. 1. Flow chart for the patient selection process. We reviewed the medical records of patients who visited Wonkwang University Hospital from January 2011 to December 2015 diagnosed with their first intracerebral hemorrhage (ICH) in the basal ganglia, thalamus, or lobes. Among them, patients who had concomitant cerebral infarction were excluded. After that, patients who met the exclusion criteria were excluded. Finally, patients who had poor single-photon emission-computed tomography (SPECT) images were excluded. 

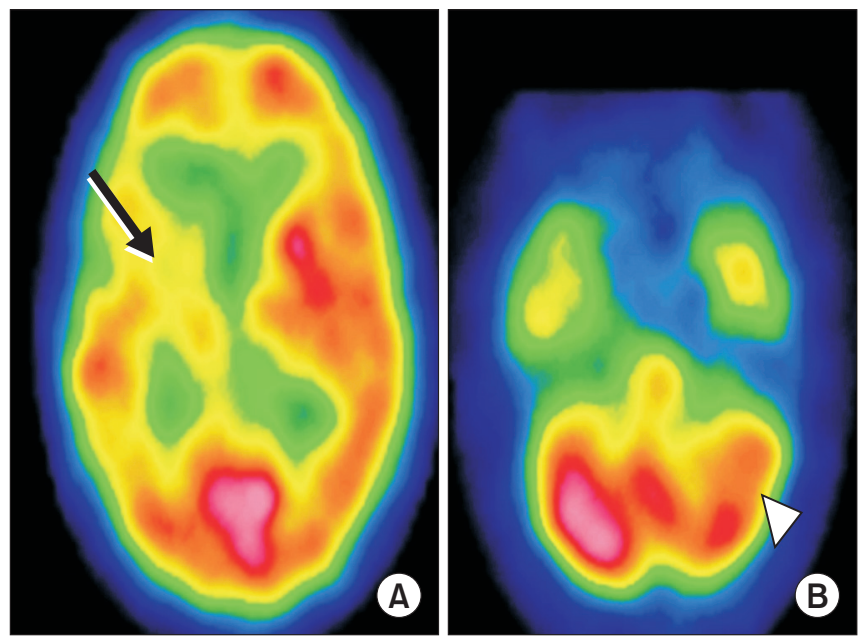

Fig. 2. Brain single-photon emission-computed tomography (SPECT) image of a 69-year-old woman. She had a right basal ganglia hemorrhage on the CT. (A) Baseline SPECT showed a severe perfusion deficit in the right basal ganglia and surrounding area. (B) Moderate hypoperfusion in the left lateral zone of the cerebellum (white arrowhead) was also noticed. In this case, asymmetry index was $24.7 \%$ and she was diagnosed to have crossed cerebellar diaschisis.

\section{Determination of CCD}

SPECT was performed 60 minutes after intravenous injection of $555 \mathrm{MBq}$ of ${ }^{99 \mathrm{~m}} \mathrm{Tc}-\mathrm{HMPAO}$ using a dual-head detector gamma camera (Millennium MG; GE Medical System, Waukesha, WI, USA). SPECT images were acquired using a low-energy high-resolution parallel-hole collimator with a $\gamma$-ray energy window of $140 \mathrm{keV} \pm 10 \%$ in a $128 \times 128$ matrix size. Sixty-four step and shoot images were obtained at intervals of $2.8^{\circ}$ for 15 seconds per step. SPECT images were reconstructed with two iterations using an ordered subset expectation maximization algorithm and regularized with a Butterworth filter.

Based on the neural linkage of the cerebral cortex to the deep cerebellar nuclei, we measured the perfusion asymmetry in the lateral zone of both cerebellar hemispheres, which is densely interconnected with the cerebral cortex [18] and associated with limb movement $[19,20]$. This area was shown to be related to the neurological outcome and is a better indicator than the medial zone when measuring CCD [8]. Regions of interest (ROIs) at sequential 3 axial slices showing prominent perfusion asymmetry were drawn by a nuclear medicine physician (Fig. 3). Then, the mean counts per pixel of ROIs were quantita-

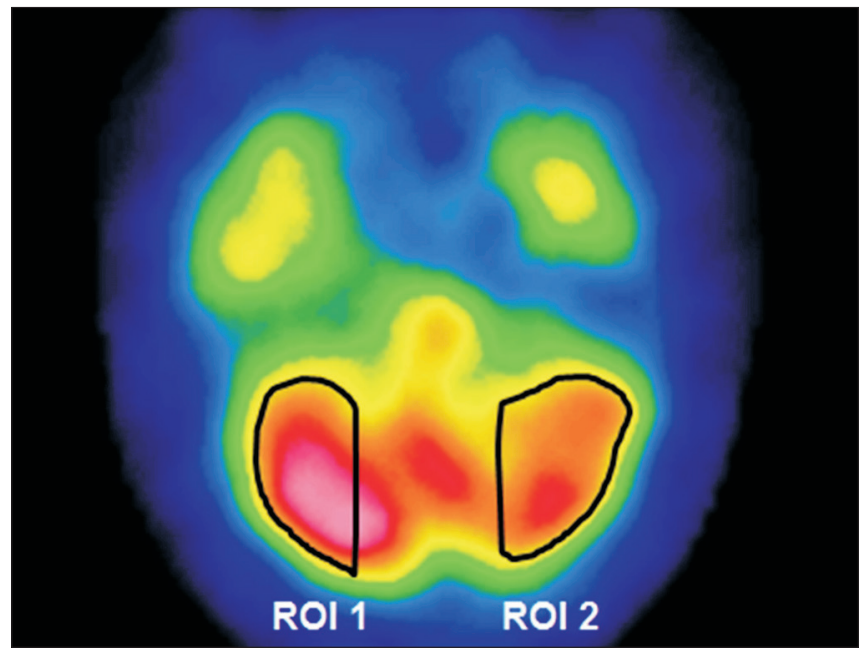

Fig. 3. Determination of the presence of crossed cerebellar diaschisis (CCD). Regions of interest (ROI) were drawn in the lateral zone of the cerebellum. The mean counts per pixel of ROIs were quantitatively measured in sequential 3 axial images showing prominent cerebellar perfusion asymmetry and mean value was calculated. The cerebellar interhemispheric asymmetry index (AI) was measured. Finally, CCD has confirmed if AI was more than $10 \%$.

tively measured and averaged. Finally, the cerebellar interhemispheric asymmetry index (AI) of the lateral zone was calculated as follow $[21,22]$ :

$$
\mathrm{AI}(\%)=\frac{I C L-C C L}{\frac{I C L+C C L}{2}} \times 100 \%
$$

where ICL is the mean counts/pixel of one zone in the ipsilateral cerebellar hemisphere and CCL is the mean counts/pixel of the corresponding zone in the contralateral cerebellar hemisphere. CCD was considered to be present if the AI of a certain zone was larger than $10 \%$ $[5,11]$.

\section{Method of investigating potential risk factors relevant to $C C D$}

Factors that may be associated with CCD were examined by reviewing the medical records of patients who met the inclusion criteria. They were subdivided into the following two groups: clinical factors and radiologic factors. Clinical factors included age, sex, body mass index (BMI), past history of hypertension (HTN), past history of diabetes mellitus (DM), past history of hyperlipidemia, 
initial Glasgow Coma Scale (GCS) score, estimated glomerular filtration rate (eGFR), and functional outcomes, including the Fugl-Meyer Assessment (FMA), the Korean version of Mini-Mental State Examination (K-MMSE), the Korean version of the Modified Barthel Index (K-MBI), and then Functional Ambulatory Category (FAC), which were assessed when patients were referred to and underwent SPECT. The initial GCS score was assessed by a neurosurgeon when the patient arrived at the ER. eGFR was calculated by the Modification of Diet in Renal Disease (MDRD) [23]. Radiologic factors included the concomitance of intraventricular hemorrhage (IVH), lesion side, location of the lesion, and hemorrhagic volume. These radiologic factors were collected based on the results of CT upon the first visit to the ER. To investigate the association between the occurrence of CCD and location of the lesion, lesions were subdivided into basal ganglia and non-basal ganglia. Hemorrhagic volume was calculated by a neuroradiologist using the $\mathrm{ABC} / 2$ method [24].

Relevancy between CCD and functional recovery after 6 months

Functional parameters were classified into the following four categories: motor function, cognitive function, ADL, and ambulation. To quantify and assess motor function, the FMA was used. The FMA is known to be a useful evaluation tool that assesses the degree of motor impairment after stroke [25]. It has the following five domains: motor function, sensory function, balance, the range of motion, and pain. Of these domains, because we aimed to measure motor function in patients with ICH, we used the motor domain scale, which consists of two parts (the upper extremity and lower extremity). Scores for the upper extremity and lower extremity were summed into a total FMA motor score. To evaluate cognitive function, the K-MMSE was used. To assess ADLs, the K-MBI was measured. The K-MBI has 10 subjects measuring individual performance and ADL capacity. Lastly, to assess ambulation, the FAC was used. The FAC uses six categories to classify the patient's ability to ambulate, which range from nonfunctional ambulation to independent gait [26]. These parameters were investigated by reviewing the medical records and assessed initially when the patients underwent SPECT and 6 months after onset.

Factors which may influence the degree of improvement in functional outcomes were investigated by re- viewing medical records. Initial grade of paresis is an important prognostic factor of motor recovery $[27,28]$. Cognition was affected by age $[29,30]$ in the previous studies. Improvement of ADL was influenced by age [31]. Recovery of walking function was related to the degree of walking dysfunction at onset [32].

\section{Statistical analysis}

The fundamental characteristics of the study groups were examined by the Kolmogorov-Smirnov test to verify a normal distribution. To compare the differences between the CCD-positive group and CCD-negative group, the chi-square $\left(\chi^{2}\right)$ test or Fisher exact test was used for categorical variables; the independent t-test or MannWhitney test was used for continuous variables. Items which resulted in a p-value less than 0.1 in the previous univariate analysis were further analyzed by multivariate logistic regression to confirm the relevant factors. All functional outcomes recorded when the patients underwent SPECT and 6 months after onset were analyzed to establish pre-post differences in each group by using the paired t-test. The degree of improvement in functional outcomes was analyzed to establish differences between two groups by using the independent t-test. After that, to assess the effect of CCD on the recovery of functional outcomes after 6 months, multiple linear regression analysis was performed. Besides occurrence of CCD, factors which were shown to be relevant with the occurrence of CCD in this study and which were considered closely related with functional outcomes in the previous studies were set as independent variables in this analysis. Statistical analysis was performed with SPSS version 22.0 (IBM Inc., Armonk, New York, USA) and p-values $<0.05$ was considered statistically significant.

\section{RESULTS}

Eighty-two patients had first-ever ICH in the basal ganglia, thalamus, or lobes. Among these patients, three patients were excluded due to their past history. After that, 79 patients were included in this study. However, 5 patients were excluded due to poor SPECT image quality, which made analysis impossible. Thus, 74 patients were finally included; CCD was found to be present in 34 cases (45.9\%). In the CCD-positive group and CCD-negative group, the mean AI was $16.7 \% \pm 5.4 \%$ and $3.9 \% \pm 3.9 \%$, 
respectively (Table 1 ). The $95 \%$ confidence interval (CI) of AI was 14.9-18.5 in CCD-positive group and 2.7-5.1 in CCD-negative group. All patients underwent SPECT in $42.8 \pm 29.5$ days after onset in the CCD-positive group, and $53.2 \pm 45.6$ days after beginning in the CCD-negative group. There was no significant difference in elapsed

Table 1. Findings of cerebellar perfusion using SPECT

\begin{tabular}{lccccccc}
\hline & Number (\%) & $\begin{array}{c}\text { Ipsilateral } \\
\text { counts/pixel }\end{array}$ & $\begin{array}{c}\text { Contralateral } \\
\text { counts/pixel }\end{array}$ & AI (\%) & $\mathbf{9 5 \%}$ CI & $\begin{array}{c}\text { Elapsed time for } \\
\text { SPECT (day) }\end{array}$ & p-value $^{\text {a) }}$ \\
\hline CCD (+) & $34(45.9)$ & $46.8 \pm 13.7$ & $39.6 \pm 12.1$ & $16.7 \pm 5.4$ & $14.9-18.5$ & $42.8 \pm 29.5$ & 0.245 \\
\hline CCD (-) & $40(54.1)$ & $51.2 \pm 12.6$ & $49.3 \pm 12.8$ & $3.9 \pm 3.9$ & $2.7-5.1$ & $53.2 \pm 45.6$ & \\
\hline
\end{tabular}

SPECT, single photon emission computed tomography; AI, asymmetry index; CI, confidence interval; CCD, crossed cerebellar diaschisis.

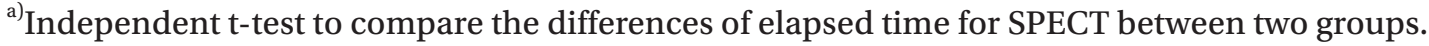

Table 2. Baseline characteristics of the participants

\begin{tabular}{|c|c|c|c|}
\hline & $\operatorname{CCD}(+)(n=34)$ & $\operatorname{CCD}(-)(n=40)$ & p-value \\
\hline \multicolumn{4}{|l|}{ Clinical factors } \\
\hline Age (yr) & $56.7 \pm 14.1$ & $61.3 \pm 14.3$ & 0.177 \\
\hline \multicolumn{4}{|l|}{ Sex } \\
\hline Male & $23(67.6)$ & $22(55.0)$ & 0.267 \\
\hline Female & $11(32.4)$ & $18(45.0)$ & \\
\hline BMI $\left(\mathrm{kg} / \mathrm{m}^{2}\right)$ & $23.9 \pm 3.1$ & $23.3 \pm 2.6$ & 0.111 \\
\hline Hypertension & $26(76.4)$ & $31(77.5)$ & 0.916 \\
\hline Diabetes mellitus & $4(11.7)$ & $5(12.5)$ & 1.000 \\
\hline Hyperlipidemia & $13(38.2)$ & $11(27.5)$ & 0.470 \\
\hline Initial GCS score & $11.1 \pm 3.8$ & $12.5 \pm 2.9$ & $0.071^{*}$ \\
\hline $\mathrm{eGFR}\left(\mathrm{mL} / \mathrm{min} / 1.73 \mathrm{~m}^{2}\right)$ & $109.6 \pm 52.2$ & $97.7 \pm 31.3$ & 0.438 \\
\hline \multicolumn{4}{|l|}{ Functional outcomes $^{\text {a) }}$} \\
\hline FMA & $12.6 \pm 15.1$ & $34.7 \pm 27.3$ & $<0.001^{*}$ \\
\hline K-MMSE & $17.8 \pm 9.5$ & $18.4 \pm 7.9$ & 0.786 \\
\hline K-MBI & $24.2 \pm 19.8$ & $36.1 \pm 23.9$ & $0.025^{*}$ \\
\hline FAC & $0.7 \pm 0.7$ & $1.1 \pm 1.0$ & 0.158 \\
\hline \multicolumn{4}{|l|}{ Radiologic factors } \\
\hline IVH & $20(58.5)$ & $17(42.5)$ & 0.162 \\
\hline Lesion side & & & 0.242 \\
\hline Right & $16(47.1)$ & $25(62.5)$ & \\
\hline Left & $18(52.9)$ & $15(37.5)$ & \\
\hline Location of lesion & & & $0.027^{*}$ \\
\hline BG & $28(82.3)$ & $21(52.5)$ & \\
\hline Non-BG & $6(17.7)$ & $19(47.5)$ & \\
\hline Volume of hemorrhage $(\mathrm{mL})$ & $18.5 \pm 14.2$ & $8.0 \pm 7.8$ & $<0.001^{*}$ \\
\hline
\end{tabular}

Values are presented as mean \pm standard deviation or number (\%).

CCD, crossed cerebellar diaschisis; BMI, body mass index; GCS, Glasgow Coma Scale; eGFR, estimated glomerular filtration rate; FMA, Fugl-Meyer Assessment; K-MMSE, Korean version of Mini-Mental State Examination; K-MBI, Korean version of Modified Barthel Index; FAC, Functional Ambulatory Category; IVH, intraventricular hemorrhage; BG, basal ganglia.

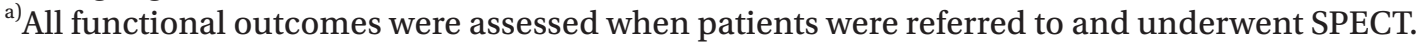
${ }^{*} \mathrm{p}<0.1$. 
time before SPECT between the two groups.

\section{Presumable risk factors related to CCD}

Initial GCS score, FMA score, and K-MBI score assessed at the time of SPECT measurement, the location of the lesion, and hemorrhagic volume showed statistically significant differences between two groups after univariate analysis (Table 2). The initial GCS score in the CCDpositive group and the CCD-negative group was $11.1 \pm 3.8$ and $12.5 \pm 2.9$, respectively ( $\mathrm{p}=0.071$ ). The FMA score in the CCD-positive group and the CCD-negative group was $12.6 \pm 15.1$ and $34.7 \pm 27.3$, respectively $(\mathrm{p}<0.001)$. The $\mathrm{K}-\mathrm{MBI}$ score in the CCD-positive group and the CCDnegative group was $24.2 \pm 19.8$ and $36.1 \pm 23.9$, respectively $(\mathrm{p}=0.025)$. Other clinical factors, including age, sex, BMI, past history of HTN, past history of DM, past history of hyperlipidemia, eGFR, K-MMSE score and FAC score assessed at the time of SPECT measurement, showed no significant differences between two groups. Among radiologic factors, only the lesion location and hemorrhagic volume showed significant differences between groups ( $\mathrm{p}=0.027$ and $\mathrm{p}<0.001$, respectively). Lesion locations were as follows: 28 in the basal ganglia $(82.3 \%)$ and 6 in the non-basal ganglia $(17.7 \%)$ in the CCD-positive group, and 21 in the basal ganglia (52.5\%) and 19 in the non-basal ganglia (47.5\%) in the CCD-negative group. Regarding hemorrhagic volume, the volume recorded in the CCD-positive group and CCD-negative group was $18.5 \pm 14.2 \mathrm{~mL}$ and $8.0 \pm 7.8 \mathrm{~mL}$, respectively. Other factors such as the concomitance of IVH and lesion side, were not significantly different between two groups.

Multivariate logistic regression analysis was conducted with factors that were significantly different in the univariate analysis (Table 3). The abovementioned factors were set as independent variables, and the occurrence of CCD was set as a dependent variable. Regarding lesion location, CCD was 6.1 times more likely to happen in basal ganglia hemorrhages than non-basal ganglia hem-

Table 3. Factors relevant to the crossed cerebellar diaschisis after multivariate analysis

\begin{tabular}{llll}
\hline \multicolumn{1}{c}{ Variable } & OR & $\mathbf{9 5 \%}$ CI & p-value \\
\hline Initial GCS score & 0.920 & $0.739-1.134$ & 0.501 \\
FMA score at the time of SPECT measurement & 0.996 & $0.937-1.453$ & 0.128 \\
K-MBI score at the time of SPECT measurement & 1.009 & $0.203-1.521$ & 0.648 \\
Basal ganglia & 6.138 & $1.524-24.720$ & $0.011^{*}$ \\
Hemorrhage volume & 1.055 & $1.021-1.148$ & $0.046^{*}$ \\
\hline
\end{tabular}

OR, odd ratio; CI, confidence interval; GCS, Glasgow Coma Scale; FMA, Fugl-Meyer Assessment; SPECT, single photon emission computed tomography; K-MBI, the Korean version of Modified Barthel Index. ${ }^{*} \mathrm{p}<0.05$.

Table 4. Change in functional outcome measures in the CCD positive and negative groups

\begin{tabular}{|c|c|c|c|c|c|c|c|}
\hline & \multicolumn{3}{|c|}{$\operatorname{CCD}(+)(n=34)$} & \multicolumn{3}{|c|}{$\operatorname{CCD}(-)(n=40)$} & \multirow[b]{2}{*}{ p-value } \\
\hline & $\begin{array}{l}\text { At the initial } \\
\text { assessment }{ }^{\text {a) }}\end{array}$ & $\begin{array}{c}6 \text { months } \\
\text { after onset }\end{array}$ & p-value e $^{\text {) }}$ & $\begin{array}{l}\text { At the initial } \\
\text { assessment }^{\text {a) }}\end{array}$ & $\begin{array}{c}6 \text { months } \\
\text { after onset }\end{array}$ & p-value ${ }^{\text {b) }}$ & \\
\hline FMA & $12.6 \pm 15.1$ & $20.6 \pm 17.3$ & $0.005^{*}$ & $34.7 \pm 27.3$ & $46.6 \pm 27.1$ & $<0.001^{*}$ & $0.032^{*}$ \\
\hline K-MMSE & $17.8 \pm 9.5$ & $19.5 \pm 9.7$ & $<0.001^{*}$ & $18.4 \pm 7.9$ & $22.3 \pm 6.2$ & $<0.001^{*}$ & 0.928 \\
\hline K-MBI & $24.2 \pm 19.8$ & $39.7 \pm 25.2$ & $<0.001^{*}$ & $36.1 \pm 23.9$ & $51.9 \pm 24.5$ & $<0.001^{*}$ & 0.178 \\
\hline FAC & $0.7 \pm 0.7$ & $1.3 \pm 1.0$ & $<0.001^{*}$ & $1.1 \pm 1.0$ & $2.0 \pm 1.2$ & $<0.001^{*}$ & 0.379 \\
\hline
\end{tabular}

Values are presented as mean \pm standard deviation.

CCD, crossed cerebellar diaschisis; FMA, Fugl-Meyer Assessment; K-MMSE, the Korean version of Mini-Mental State Examination; K-MBI, the Korean version of Modified Barthel Index; FAC, Functional Ambulatory Category.

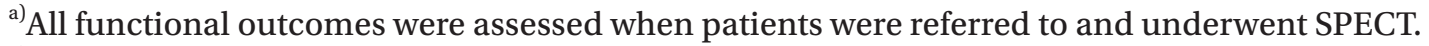

${ }^{b)}$ Paired t-test to analyze pre-post differences between assessment at the time of SPECT measurement and 6 months after onset in each group.

${ }^{\mathrm{c})}$ Independent t-test to analyze differences in degree of improvements in functional outcomes between two groups. ${ }^{*} \mathrm{p}<0.05$. 
orrhages (odds ratio $[\mathrm{OR}]=6.138 ; 95 \% \mathrm{CI}, 1.524-24.720$; $\mathrm{p}=0.011)$. CCD was also significantly related to high hemorrhagic volume (OR=1.055; 95\% CI, 1.021-1.148; $\mathrm{p}=0.046)$. Of the factors studied, the location of the lesion and hemorrhagic volume were found to be the most accurate predictors of risk of CCD.

\section{Relationship between CCD and functional recovery} after 6 months

Six months after onset, motor function, cognitive function, ADL, and ambulation improved significantly compared with the assessments performed at the timing when patients underwent SPECT in both groups (Table 4). The difference of degree of improvement in FMA score was significant between the CCD-positive group and CCD-negative group $(\mathrm{p}=0.032)$. There was no significant difference in other functional outcomes between the two groups. To verify the relationship between the differences in degree of improvement of FMA score and CCD, multivariate linear regression analysis was performed (Table 5). CCD was associated with poor improvements of FMA score over 6 months $\left(\mathrm{R}^{2}=0.152, \mathrm{p}=0.036\right)$. There were no significant correlations between CCD and the degree of improvement in K-MMSE, K-MBI, and FAC during the 6

Table 5. Relations between CCD and degree of improvement in functional domains

\begin{tabular}{lcccc}
\hline & $\Delta$ FMA $^{\text {a) }}$ & $\Delta$ K-MMSE $^{\text {b) }}$ & $\Delta \mathbf{K}^{-M_{B} I^{\mathbf{c}}}$ & $\Delta$ FAC $^{\text {d) }}$ \\
\hline CCD & & & & \\
B & -5.540 & 0.269 & 1.924 & -0.163 \\
\hline p-value & $0.036^{*}$ & 0.886 & 0.612 & 0.428 \\
Adjusted $\mathrm{R}^{2}$ & 0.152 & 0.032 & 0.026 & 0.001 \\
\hline
\end{tabular}

CCD, crossed cerebellar diaschisis; FMA, Fugl-Meyer Assessment; K-MMSE, Korean version of Mini-Mental State Examination; K-MBI, Korean version of Modified Barthel Index; FAC, Functional Ambulatory Category; $\Delta$, differences of functional outcome between initial assessment when the patients underwent SPECT and 6 months after the onset.

${ }^{a}$ Adjusted variables: FMA score when the patients underwent SPECT, location of lesion, volume of hemorrhage.

${ }^{b)}$ Adjusted variables: age, location of lesion, volume of hemorrhage.

${ }^{c}$ Adjusted variables: age, location of lesion, volume of hemorrhage.

${ }^{d)}$ Adjusted variables: FAC score when the patients underwent SPECT, location of lesion, volume of hemorrhage. ${ }^{*} \mathrm{p}<0.05$. months after onset.

\section{DISCUSSION}

In this study, we aimed to investigate the incidence of CCD and identify the correlation between CCD and functional recovery. In our study, CCD was observed in $45.9 \%$ of the patients. This was similar to the previously reported prevalence of CCD [2,5]. Additionally, our study demonstrated that ICH volume and lesion location may be predisposing factors of CCD and that the presence of CCD may affect motor outcomes at 6 months after a stroke.

Our results suggest that lesion location and hemorrhagic volume are related to the occurrence of CCD. Many previous studies have attempted to reveal possible risk factors associated with the occurrence of CCD. Prior studies aimed at evaluating ischemic stroke have shown that volume $[8,9,17]$, and lesion location $[2,5]$ may be predisposing factors for CCD. Liu et al. [8] concluded that CCD was correlated with a large infarction volume. Sobesky et al. [9] reported that the existence of CCD is related to supratentorial hypoperfusion volume in the early stage of middle cerebral artery infarction, but not to the severity of brain injury. Lin et al. [33] reported that lesion volume might account for the presence of CCD. Our findings support these preceding studies. Regarding lesion location, basal ganglia [21], thalamus [7], postcentral, supramarginal [11], frontoparietal lobe [5] were reported to be related to CCD. In our study, hemorrhage in the basal ganglia showed a higher incidence of CCD than hemorrhage in the non-basal ganglia. This result was similar to the previous study [21]. Basal ganglia had diverse neuronal connections which reached the other areas of the brain. Interruption of these neuronal connections might be associated with the occurrence of CCD.

To assess the correlation between stroke severity and CCD, the modified Canadian Neurological Scale [14] and Scandinavian Neurological Scale [13] have been used in previous studies. The authors found significant associations between CCD and stroke severity and concluded that stroke severity is related to CCD. In our study, to investigate the influence of stroke severity, the initial GCS score and FMA score were used; contrary to prior studies, no relationship with CCD was evident. This might be explained by the differences between hemorrhagic stroke 
and ischemic stroke, or the difference between GCS, FMA score and other tools such as modified Canadian Neurological scale and Scandinavian Neurological scale. Additionally, laterality did not show a correlation with CCD. Contrary to a report that the left side is related to CCD [2], we could not find any association between leftside lesions and CCD. It is unclear whether these results are influenced by heterogeneous groups or the number of participants, making them different with that of previous studies.

Our results are consistent with those of previous studies that concluded that the occurrence of CCD had a close association with motor recovery $[12,16,17]$. Chon et al. [12] proposed that CCD may represent a degree of motor function, rather than ADLs or a cognitive aspect. They showed that MBI and MMSE were not related to CCD. This is similar to the results of a study by Choi et al. [16]. Both authors elucidated that CCD is a prognostic factor for motor function. Another study suggested that functional recovery of the hand after stroke was associated with CCD [17]. The authors assessed the function of the hand and finger and compared them with functional magnetic resonance imaging (MRI). Interestingly, other researchers used the Brunnstrom stage to establish the clinical usefulness of CCD [34] and concluded that CCD and Brunnstrom stage have a close correlation.

Some authors have demonstrated that CCD has no prognostic value in stroke outcome. Infeld et al. [14] showed that CCD could not predict brain recovery after stroke. They used the Barthel index to establish whether CCD could predict stroke outcome. Laloux et al. [15] showed no association between CCD and functional status using the Rankin scale. De Reuck et al. [35] concluded that the existence of CCD had no clinical significance when they assessed CCD with the Orgogozo stroke scale. These disagreements may be attributed to the heterogeneity of the experimental group, variable timing of CCD measurement, or diversity of the assessment tools used by the previous researchers.

There were several limitations of this study. First, this study was designed as a retrospective study which produces selection bias. Second, as this was a single-center study, only small populations were available. Third, in addition to CCD, functional outcomes after 6 months from the onset of stroke might be affected by the intensity of rehabilitation [36], comorbidity, and complications. A stratified analysis should be performed in larger prospective studies to overcome these limitations.

In conclusion, CCD was seen in $45.9 \%$ of patients who experienced their first intracerebral hemorrhage. Lesion location and hemorrhagic volume were predisposing factors for CCD. In this study, in the presence of CCD, patients had poorer motor outcomes after 6 months from onset than those without CCD.

\section{CONFLICT OF INTEREST}

No potential conflict of interest relevant to this article was reported.

\section{ACKNOWLEDGMENTS}

This paper was supported by the Wonkwang Institute of Medical Science in 2016.

\section{REFERENCES}

1. Baron JC, Bousser MG, Comar D, Castaigne P. "Crossed cerebellar diaschisis" in human supratentorial brain infarction. Trans Am Neurol Assoc 1981;105: 459-61.

2. Sommer WH, Bollwein C, Thierfelder KM, Baumann A, Janssen H, Ertl-Wagner B, et al. Crossed cerebellar diaschisis in patients with acute middle cerebral artery infarction: occurrence and perfusion characteristics. J Cereb Blood Flow Metab 2016;36:743-54.

3. Feeney DM, Baron JC. Diaschisis. Stroke 1986;17:81730.

4. Tien RD, Ashdown BC. Crossed cerebellar diaschisis and crossed cerebellar atrophy: correlation of MR findings, clinical symptoms, and supratentorial diseases in 26 patients. AJR Am J Roentgenol 1992;158: 1155-9.

5. Kim SE, Choi CW, Yoon BW, Chung JK, Roh JH, Lee $\mathrm{MC}$, et al. Crossed-cerebellar diaschisis in cerebral infarction: technetium-99m-HMPAO SPECT and MRI. J Nucl Med 1997;38:14-9.

6. Di Piero V, Chollet F, Dolan RJ, Thomas DJ, Frackowiak $\mathrm{R}$. The functional nature of cerebellar diaschisis. Stroke 1990;21:1365-9.

7. Engelborghs S, Pickut BA, Marien P, Opsomer F, De Deyn PP. Crossed cerebellar diaschisis and hemiatax- 
ia after thalamic hemorrhage. J Neurol 2000;247:4767.

8. Liu Y, Karonen JO, Nuutinen J, Vanninen E, Kuikka JT, Vanninen RL. Crossed cerebellar diaschisis in acute ischemic stroke: a study with serial SPECT and MRI. J Cereb Blood Flow Metab 2007;27:1724-32.

9. Sobesky J, Thiel A, Ghaemi M, Hilker RH, Rudolf J, Jacobs AH, et al. Crossed cerebellar diaschisis in acute human stroke: a PET study of serial changes and response to supratentorial reperfusion. J Cereb Blood Flow Metab 2005;25:1685-91.

10. Forster A, Kerl HU, Goerlitz J, Wenz H, Groden C. Crossed cerebellar diaschisis in acute isolated thalamic infarction detected by dynamic susceptibility contrast perfusion MRI. PLoS One 2014;9:e88044.

11. Komaba Y, Mishina M, Utsumi K, Katayama Y, Kobayashi S, Mori O. Crossed cerebellar diaschisis in patients with cortical infarction: logistic regression analysis to control for confounding effects. Stroke 2004;35:472-6.

12. Chon JS, Chun SI, Yoo WK, Lee JD, Doh WS. Diaschisis and motor recovery in stroke patients. J Korean Acad Rehabil Med 1998;22:822-7.

13. Szilagyi G, Vas A, Kerenyi L, Nagy Z, Csiba L, Gulyas B. Correlation between crossed cerebellar diaschisis and clinical neurological scales. Acta Neurol Scand 2012; 125:373-81.

14. Infeld B, Davis SM, Lichtenstein M, Mitchell PJ, Hopper JL. Crossed cerebellar diaschisis and brain recovery after stroke. Stroke 1995;26:90-5.

15. Laloux P, Richelle F, Jamart J, De Coster P, Laterre C. Comparative correlations of HMPAO SPECT indices, neurological score, and stroke subtypes with clinical outcome in acute carotid infarcts. Stroke 1995;26:81621.

16. Choi IS, Kim JH, Lee SY, Kang KJ, Kim JH, Lee SG. The correlation between crossed cerebellar diaschisis and motor impairment of hemiplegic upper extremity in stroke patients. J Korean Acad Rehabil Med 2005;29:15-22.

17. Small SL, Hlustik P, Noll DC, Genovese C, Solodkin A. Cerebellar hemispheric activation ipsilateral to the paretic hand correlates with functional recovery after stroke. Brain 2002;125(Pt 7):1544-57.

18. Kandel ER, Schwartz JH, Jessell TM. Principles of neural science. 4th ed. New York: McGraw-Hill; 2000.
19. Chambers WW, Sprague JM. Functional localization in the cerebellum. II. Somatotopic organization in cortex and nuclei. AMA Arch Neurol Psychiatry 1955;74:65380.

20. Chambers WW, Sprague JM. Functional localization in the cerebellum. I. Organization in longitudinal cortico-nuclear zones and their contribution to the control of posture, both extrapyramidal and pyramidal. J Comp Neurol 1955;103:105-29.

21. Lim JS, Ryu YH, Kim BM, Lee JD. Crossed cerebellar diaschisis due to intracranial hematoma in basal ganglia or thalamus. J Nucl Med 1998;39:2044-7.

22. Fazekas F, Payer F, Valetitsch H, Schmidt R, Flooh E. Brain stem infarction and diaschisis: a SPECT cerebral perfusion study. Stroke 1993;24:1162-6.

23. Lee M, Saver JL, Chang KH, Liao HW, Chang SC, Ovbiagele B. Low glomerular filtration rate and risk of stroke: meta-analysis. BMJ 2010;341:c4249.

24. Kothari RU, Brott T, Broderick JP, Barsan WG, Sauerbeck LR, Zuccarello M, et al. The ABCs of measuring intracerebral hemorrhage volumes. Stroke 1996;27: 1304-5.

25. Gladstone DJ, Danells CJ, Black SE. The Fugl-Meyer assessment of motor recovery after stroke: a critical review of its measurement properties. Neurorehabil Neural Repair 2002;16:232-40.

26. Holden MK, Gill KM, Magliozzi MR, Nathan J, PiehlBaker L. Clinical gait assessment in the neurologically impaired: reliability and meaningfulness. Phys Ther 1984;64:35-40.

27. Hendricks HT, van Limbeek J, Geurts AC, Zwarts MJ. Motor recovery after stroke: a systematic review of the literature. Arch Phys Med Rehabil 2002;83:1629-37.

28. Coupar F, Pollock A, Rowe P, Weir C, Langhorne P. Predictors of upper limb recovery after stroke: a systematic review and meta-analysis. Clin Rehabil 2012; 26:291-313.

29. Gottesman RF, Hillis AE. Predictors and assessment of cognitive dysfunction resulting from ischaemic stroke. Lancet Neurol 2010;9:895-905.

30. Henon H, Durieu I, Guerouaou D, Lebert F, Pasquier F, Leys D. Poststroke dementia: incidence and relationship to prestroke cognitive decline. Neurology 2001; 57:1216-22.

31. Veerbeek JM, Kwakkel G, van Wegen EE, Ket JC, Heymans MW. Early prediction of outcome of activities 
of daily living after stroke: a systematic review. Stroke 2011;42:1482-8.

32. Jorgensen HS, Nakayama H, Raaschou HO, Olsen TS. Recovery of walking function in stroke patients: the Copenhagen Stroke Study. Arch Phys Med Rehabil 1995;76:27-32.

33. Lin DD, Kleinman JT, Wityk RJ, Gottesman RF, Hillis $\mathrm{AE}$, Lee AW, et al. Crossed cerebellar diaschisis in acute stroke detected by dynamic susceptibility contrast MR perfusion imaging. AJNR Am J Neuroradiol 2009;30:710-5.

34. Watanabe H, Niwa N, Kanai M, Sasaki S. The relation between crossed cerebellar blood flow and severities of hemiplegia: a technetium-(99m) hexamethylpropylene amine oxine SPECT study using Patlak plot method. Tohoku J Exp Med 1996;179:177-81.

35. De Reuck J, Decoo D, Lemahieu I, Strijckmans K, Goethals P, Van Maele G. Crossed cerebellar diaschisis after middle cerebral artery infarction. Clin Neurol Neurosurg 1997;99:11-6.

36. Kwakkel G, Wagenaar RC, Koelman TW, Lankhorst GJ, Koetsier JC. Effects of intensity of rehabilitation after stroke: a research synthesis. Stroke 1997;28:1550-6. 